\title{
Inspiratory Vital Capacity
}

National Cancer Institute

\section{Source}

National Cancer Institute. Inspiratory Vital Capacity. NCI Thesaurus. Code C124423.

The maximum volume of gas an individual can inhale from the point of maximal exhalation. 